\title{
KEY TO MAIN SYMBOLS
}

\section{Consonants}

\begin{tabular}{|c|c|c|c|c|c|}
\hline \multicolumn{2}{|c|}{ Voiceless stops } & \multicolumn{3}{|c|}{ Voiced stops } & Nasal voiced stops \\
\hline [p] as in & pat & [b] & as in & bad & {$[\mathrm{m}]$ as in mum } \\
\hline as & tap & {$[\mathrm{d}$} & as & did & as in \\
\hline as in & clock & [g] & as in & gig & sing, think \\
\hline
\end{tabular}

\section{Voiceless fricatives}

[f] as in fat

$[\theta]$ as in thigh, theta, breath

[s] as in sip, hiss, cats

$\left[\int\right]$ as in ship, station

[h] as in hot
Voiced fricatives

[v] as in van

[ð] as in thy, that, breathe

[z] as in zoo, buzz, dogs

[3] as in rouge, leisure

Voiceless affricate

\section{Voiced affricate}

$\left[\mathrm{t} \int\right]$ as in chip, catch [dz] as in judge, George, courageous

Approximants (all voiced)

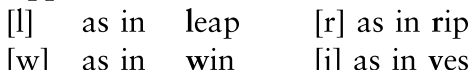

[j] as in yes

Vowels (note that the vowels are all voiced approximants)

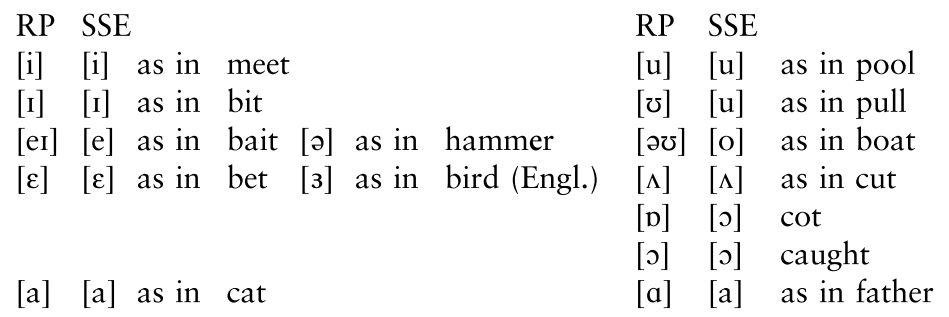




\section{Diphthongs}

RP

[aI] [Ai]

$[\mathrm{av}] \quad[\mathrm{uu}]$

[эг] [วе]

as in time

[Iə]

[Iə] as in idea, fear

(Also [eI] as in bait and [əच] as in boat for RP speakers) 